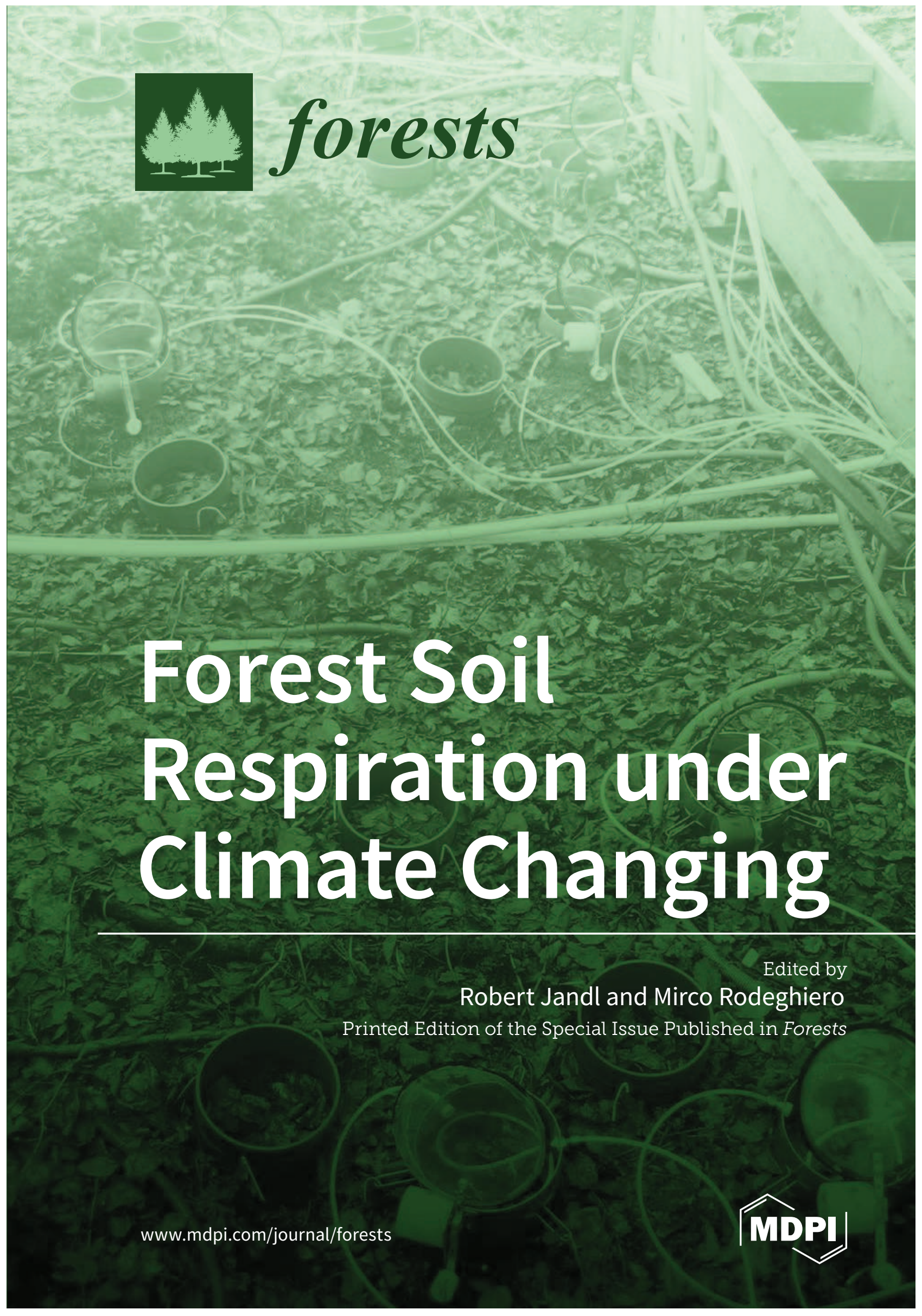




\section{Forest Soil Respiration under Climate Changing}





\section{Forest Soil Respiration under Climate Changing}

Special Issue Editors

Robert Jandl

Mirco Rodeghiero

MDPI • Basel • Beijing • Wuhan • Barcelona • Belgrade

\section{MDPI}


Special Issue Editors

Robert Jandl

Austrian Forest Research Center (BFW)

Austria

Mirco Rodeghiero

Research and Innovation Centre, Fondazione Edmund Mach San Michele all'Adige,

Italy

Editorial Office

MDPI

St. Alban-Anlage 66

Basel, Switzerland

This is a reprint of articles from the Special Issue published online in the open access journal Forests (ISSN 2079-9284) from 2016 to 2017 (available at: http://www.mdpi.com/journal/forests/special_ issues/soil respiration)

For citation purposes, cite each article independently as indicated on the article page online and as indicated below:

LastName, A.A.; LastName, B.B.; LastName, C.C. Article Title. Journal Name Year, Article Number, Page Range.

ISBN 978-3-03897-178-8 (Pbk)

ISBN 978-3-03897-179-5 (PDF)

Articles in this volume are Open Access and distributed under the Creative Commons Attribution (CC BY) license, which allows users to download, copy and build upon published articles even for commercial purposes, as long as the author and publisher are properly credited, which ensures maximum dissemination and a wider impact of our publications. The book taken as a whole is (C) 2018 MDPI, Basel, Switzerland, distributed under the terms and conditions of the Creative Commons license CC BY-NC-ND (http:/ / creativecommons.org/licenses/by-nc-nd/4.0/). 


\section{Contents}

About the Special Issue Editors . . . . . . . . . . . . . . . . . vii

Preface to "Forest Soil Respiration under Climate Changing" . . . . . . . . . . . . . . . . ix

Sergio Marconi, Tommaso Chiti, Angelo Nolè, Riccardo Valentini and Alessio Collalti

The Role of Respiration in Estimation of Net Carbon Cycle: Coupling Soil Carbon Dynamics and Canopy Turnover in a Novel Version of 3D-CMCC Forest Ecosystem Model

Reprinted from: Forests 2017, 8, 220, doi: 10.3390/f8060220 . . . . . . . . . . . . . . . . . .

Guanlin Li, Seongjun Kim, Seung Hyun Han, Hanna Chang and Yowhan Son

Effect of Soil Moisture on the Response of Soil Respiration to Open-Field Experimental Warming and Precipitation Manipulation

Reprinted from: Forests 2017, 8, 56, doi: 10.3390/f8030056 . . . . . . . . . . . . . . . . . . .

Salwan M. J. Al-Maliki, David L. Jones, Douglas L. Godbold, Dylan Gwynn-Jones and John Scullion

Elevated $\mathrm{CO}_{2}$ and Tree Species Affect Microbial Activity and Associated Aggregate Stability in Soil Amended with Litter

Reprinted from: Forests 2017, 8, 70, doi: 10.3390/f8030070 . . . . . . . . . . . . . . . . . .

Chao-Ting Chang, Dominik Sperlich, Santiago Sabaté, Elisenda Sánchez-Costa, Miriam Cotillas, Josep Maria Espelta and Carlos Gracia

Mitigating the Stress of Drought on Soil Respiration by Selective Thinning: Contrasting Effects of Drought on Soil Respiration of Two Oak Species in a Mediterranean Forest

Reprinted from: Forests 2016, 7, 263, doi: 10.3390/f7110263 . . . . . . . . . . . . . . . . .

Lin Hou, Zhe Li, Chunlin Luo, Longlong Bai and Ningning Dong

Optimization Forest Thinning Measures for Carbon Budget in a Mixed Pine-Oak Stand of the Qingling Mountains, China: A Case Study

Reprinted from: Forests 2016, 7, 272, doi: 10.3390/f7110272 . . . . . . . . . . . . . . . .

Shan Yin, Xianxian Zhang, Jukka Pumpanen, Guangrong Shen, Feng Xiong and Chunjiang Liu

Seasonal Variation in Soil Greenhouse Gas Emissions at Three Age-Stages of Dawn Redwood (Metasequoia glyptostroboides) Stands in an Alluvial Island, Eastern China

Reprinted from: Forests 2016, 7, 256, doi: 10.3390/f7110256 . . . . . . . . . . . . . . . .

Jaeyeob Jeong, Nanthi Bolan and Choonsig Kim

Heterotrophic Soil Respiration Affected by Compound Fertilizer Types in Red Pine (Pinus densiflora S. et Z.) Stands of Korea

Reprinted from: Forests 2016, 7, 309, doi: 10.3390/f7120309 . . . . . . . . . . . . . . .

Vilanee Suchewaboripont, Masaki Ando, Shinpei Yoshitake, Yasuo Iimura, Mitsuru Hirota and Toshiyuki Ohtsuka

Spatial Upscaling of Soil Respiration under a Complex Canopy Structure in an Old-Growth Deciduous Forest, Central Japan

Reprinted from: Forests 2017, 8, 36, doi: 10.3390/f8020036 . . . . . . . . . . . . . . . . 109

James W. Raich

Temporal Variability of Soil Respiration in Experimental Tree Plantations in Lowland Costa Rica

Reprinted from: Forests 2017, 8, 40, doi: 10.3390/f8020040 . . . . . . . . . . . . . . . . 124 
Forests Editorial Office

Erratum: Spatial Upscaling of Soil Respiration under a Complex Canopy Structure in an

Old-Growth Deciduous Forest, Central Japan; Forests 2017, 8, 36

Reprinted from: Forests 2017, 8, 71, doi: 10.3390/f8030071 . . . . . . . . . . . . . . . . . . 145

Tariq Muhammad Munir, Bhupesh Khadka, Bin Xu and Maria Strack

Partitioning Forest-Floor Respiration into Source Based Emissions in a Boreal Forested Bog:

Responses to Experimental Drought

Reprinted from: Forests 2017, 8, 75, doi: 10.3390/f8030075 . . . . . . . . . . . . . . . . . 146

Dingfang Chen, Mei Yu, Grizelle González, Xiaoming Zou and Qiong Gao

Climate Impacts on Soil Carbon Processes along an Elevation Gradient in the Tropical Luquillo

Experimental Forest

Reprinted from: Forests 2017, 8, 90, doi: 10.3390/f8030090 _ . . . . . . . . . . . . . . 163 


\section{About the Special Issue Editors}

Robert Jandl, Univ Lecturer, Dr is a forest ecologist at the Austrian Research Center for Forests and is coordinating the research activities related to climate change. His main research interest is currently the role of forest soils in climate change mitigation and the carbon dynamics in forest ecosystems of the temperate zone. Robert Jandl is a member of the commission for Climate and Airquality of the Austrian Academy of Sciences and a Board Member of the Austrian Center for Climate Change (CCCA).

Mirco Rodeghiero, Dr, Forest Ecology $\mathrm{PhD}$ is a researcher at Fondazione Edmund Mach (San Michele all'Adige, Italy). His main research activity is focused on the effects of climate change on soil carbon and nitrogen dynamics by combining physiological and pedological measurements. In particular he investigated the main determinants of soil carbon dioxide efflux in forest ecosystems. He coordinated the soil sampling campaign for the Italian National Forest Inventory and was involved in the major European integrative projects for the study of soil carbon dynamics. 



\section{Preface to "Forest Soil Respiration under Climate Changing"}

Soil respiration is a process of prime relevance for understanding the carbon cycle in forest ecosystems and for properly comprehending the role of forests in climate change mitigation. The process is divided into two components: (i) autotrophic soil respiration, i.e. the efflux of $\mathrm{CO} 2$ from the respiration of tree roots, and (ii) heterotrophic soil respiration, i.e. the efflux of $\mathrm{CO} 2$ due to respiration of soil microorganisms. A third component, the respiration of mycorrhizae, is still debated and it is not yet clear whether it should be accounted for in autotrophic or heterotrophic soil respiration, respectively, or whether it should be treated as a third component.

The rate of soil respiration is controlled by environmental factors. Expectedly, the strongest driver is soil temperature, followed by soil moisture. The relevance of either factor depends on site properties. Two papers are reinforcing this view. An asset of the paper compilation is the collection of case studies where other factors besides temperature and soil moisture are evidently greatly affecting the rate of soil respiration. The characteristics of the forest stand such as tree density, stand age, and tree species and additional soil properties such as aggregate stability are influencing soil respiration.

The book gives guidance on the current state of knowledge and helps identifying knowledge gaps for future research endeavours.

Robert Jandl, Mirco Rodeghiero Special Issue Editors 